\title{
Corrosion Inhibition of Aluminium in 2 M Phosphoric Acid Using the Essential Oil of Mentha Pulegium Leaves
}

\author{
M.S. Uwineza, ${ }^{a, *}$ M. Essahli ${ }^{b}$ and A. Lamiri ${ }^{c}$ \\ ${ }^{a}$ University Hassan I, Laboratory of Applied Chemistry and Environment, Faculty of Sciences \\ and Technology, BP 577 Settat, Morocco \\ ${ }^{b}$ University Hassan I, Department of Applied Chemistry and Environment, Faculty of Sciences \\ and Technology, BP 577 Settat, Morocco \\ ${ }^{c}$ University Hassan I, Director of the Superior School of Technology of Berrechid, B.P 218 \\ Berrechid, Morocco
}

Received 15 February 2016; accepted 23 February 2016

\begin{abstract}
The corrosion inhibition characteristics of essential oil of mentha pulegium leaves have been studied as a green inhibitor of corrosion of aluminum in $2 \mathrm{M}$ phosphoric acid using potentiodynamic polarization and electrochemical impedance spectroscopy (EIS). The effect of inhibitor concentration shows that efficiency increases with increase of concentration with maximum of $79 \%$ at $1800 \mathrm{ppm}$. Polarization curves reveal that the essential oil of mentha pulegium leaves acts as a cathodic inhibitor. The effect of temperature on aluminum corrosion behavior was also studied and thermodynamic data of activation was determined.
\end{abstract}

Keywords: corrosion, phosphoric acid, aluminum, inhibitor, mentha pulegium.

\section{Introduction}

Aluminum and its' alloys are a very important class of materials for their high technological value and a wide range of industrial applications particularly in aerospace and food industry, due to their low weight, low cost and favorable mechanical properties $[1,2]$. Aluminum and its' alloys are resistant to corrosion due to the surface forming a thin oxide layer that protects the metal against the oxidizing environments and a possible chemical attack [1, 3]. However, this corrosion resistance can be influenced by the way in which metals are used [3].

Efforts to stop or delay the maximum attack of metals in various corrosive media are made [4]. The use of green eco-friendly natural polymeric structures,

\footnotetext{
*Corresponding author. E-mail address: m.uwineza@uhp.ac.ma
} 
extracted from leaves or seeds as corrosion inhibitors, is gaining large preference and interest due to its safe effect to the environment, practical use, low cost and renewable sources of materials [4-6]. The extent of inhibition by those compounds depends on the effective organic groups and increases in the order oxygen $<$ nitrogen $<$ sulfur $<$ phosphorus $[7,8]$.

Mentha pulegium, commonly known as pennyroyal, is one of mentha species and it is a native species of Europe, North Africa, and Asia. It has been traditionally used as an antiseptic for treatment of cold, sinusitis, cholera, tuberculosis [9]. Its' essential oil is known to have biological activities such as antibacterial [10], antioxidant and antimicrobial properties [11, 12].

In this work, essential oil from mentha pulegium leaves has been studied for its' inhibition of activity on aluminum corrosion in $2 \mathrm{M}$ phosphoric acid by electrochemical methods.

\section{Experimental}

\section{Preparation of the solution}

The $2 \mathrm{M}$ phosphoric acid solution was prepared by dilution of the phosphoric acid of $85 \%$ analytical grade with distilled water. Test solutions were freshly prepared before each experiment by adding the oil directly to the corrosive media. Experiments were conducted in triplicate to ensure the reproducibility.

\section{Preparation of material}

The aluminum disc was abraded with sandpaper to different particle sizes of 400 , $600,800,1000$, and 1200, degreased with acetone, rinsed with distilled water and dried before each test.

\section{Electrochemical measures}

The electrochemical experiments were performed using an electrochemical work station. The electrochemical cell used was a conventional three-electrode compartment with a pyrex cell: aluminum as the working electrode in the form of discs cut with a geometric area of $1 \mathrm{~cm}^{2}$; platinum as a counter electrode; and a saturated calomel electrode (SCE) as the reference. The measurements are performed with an assembly comprising a potentiostat-galvanostat PGZ100 radiometer type associated with "voltamaster4" software.

\section{Tafel polarization measures}

A freshly polished disc was exposed to corrosion solution of $2 \mathrm{M}$ phosphoric acid. After a 30 minutes open-circuit potential steady-taste, the current-potential curves are obtained by potentiodynamic method; the potential applied to the disc varies continuously from $-1200 \mathrm{mV}$ to $-500 \mathrm{mV}$ with a scanning rate of $30 \mathrm{mV} /$ $\min$.

\section{Electrochemical impedance spectroscopy measures}

The electrochemical impedance spectroscopy (EIS) measures were performed with the same electrochemical system. The frequencies from $100 \mathrm{kHz}$ to $40 \mathrm{mHz}$ 
were superposed on the corrosion potential. The diagrams given in the impedances are Nyquist representation.

\section{Results}

\section{Analysis of the essential oil of mentha pulegium}

Table 1 gives the principal chemical component of the essential oil of mentha pulegium, which is mostly composed of $84,75 \%$ of pulegone (5-methyl-2propan-2-ylidene cyclohexan-1-one) and 14,72\% of geraniol (2,6-dimethyltrans-2,6-octadien-8-ol). The corresponding chromatogram is in Fig.1.

Table1. Principal chemical components of the essential oil of mentha pulegium.

\begin{tabular}{lcc}
\hline Time[min] & Area[\%] & Component \\
\hline 27.629 & 0.21 & Menthone \\
30.403 & 14.72 & Geraniol \\
30.426 & 84.75 & Pulegone \\
31.374 & 0.13 & Pulegone \\
\hline
\end{tabular}

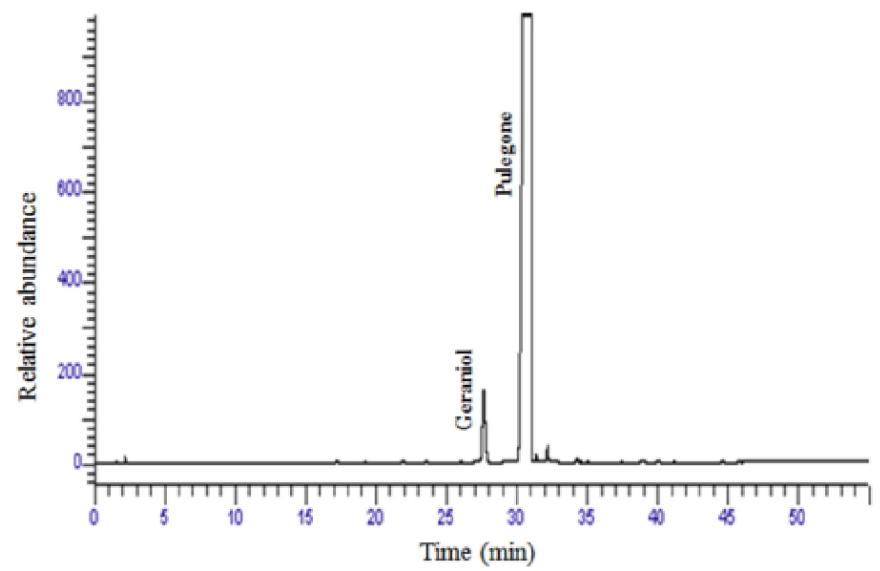

Figure 1. Chromatogram of the essential oil of mentha pulegium.

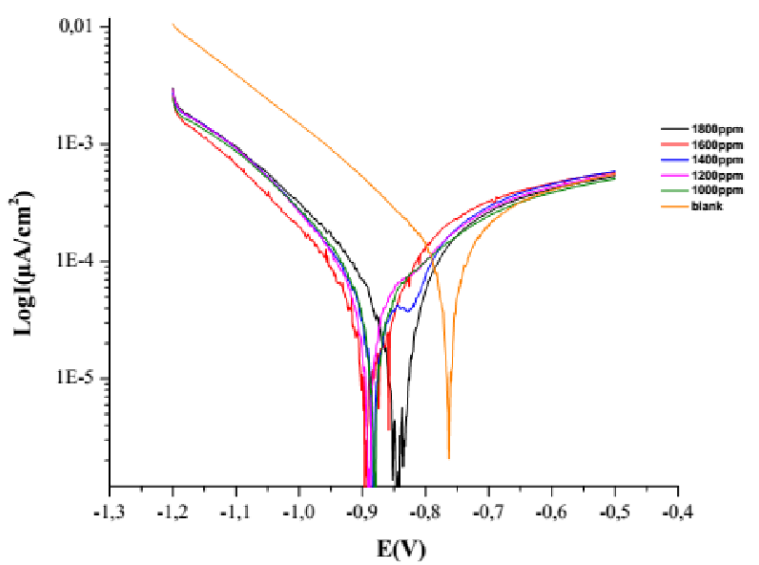

Figure 2. Tafel polarization curves for corrosion of aluminum in $2 \mathrm{M}$ phosphoric acid with and without addition of different concentrations of mentha pulegium oil at $25{ }^{\circ} \mathrm{C}$. 


\section{Polarization curves}

The polarization behavior of aluminum in $2 \mathrm{M}$ phosphoric acid with and without addition of this inhibitor is presented in Fig. 2. Electrochemical parameters, values of corrosion current (Icorr), the corrosion potential (Ecorr), and inhibitor efficiency (IE) are given in Table 2.

Table2. Polarization parameters and inhibition efficiency (EI) of aluminum in $2 \mathrm{M}$ phosphoric acid, with and without addition of different concentrations of inhibitor at 25 ${ }^{\circ} \mathrm{C}$.

\begin{tabular}{lccc}
\hline $\mathbf{C i n h}^{[\mathrm{a}]}[\mathbf{p p m}]$ & $\mathbf{E c o r r}^{[\mathbf{b ]}]}[\mathbf{m v}]$ & $\mathbf{I c o r r}_{\left.\boldsymbol{\mu} \mathbf{\mu A} / \mathbf{c m}^{2}\right]}$ & $\mathbf{E I}[\%]$ \\
\hline Blank & -765.8 & 177.7441 & ----- \\
1000 & -883.7 & 70.2838 & 60.45 \\
1200 & -892.6 & 56.5653 & 68.17 \\
1400 & -885.8 & 52.0746 & 70.70 \\
1600 & -896.8 & 46.5284 & 73.82 \\
1800 & -847.3 & 37.1355 & 79.10 \\
\hline \multicolumn{4}{c}{}
\end{tabular}

The inhibitor efficiency, in Equation 1, is defined by the following relationship:

$$
\mathrm{EI}=\frac{\mathrm{Icomr}-\mathrm{I} / \mathrm{corr}}{\mathrm{Icorr}} \times \mathbf{1 0 0}
$$

where I'corr and Icorr, respectively, represent corrosion current densities determined by extrapolation of the straight Tafel corrosion potential, with and without addition of inhibitor.

\section{Electrochemical impedance spectroscopy}

Electrochemical impedance (EIS) is a technique with a small perturbative signal, and the surface damage of the sample is very little [13]. Besides, the corrosion mechanism can be estimated by analyzing the measured electrochemical impedance spectrum.

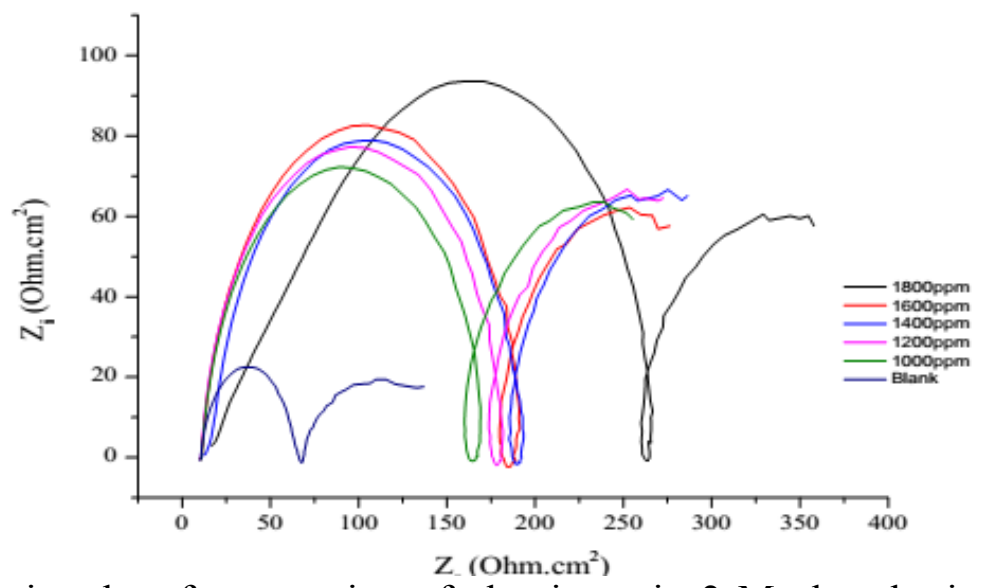

Figure 3. Nyquist plots for corrosion of aluminum in $2 \mathrm{M}$ phosphoric acid with and without addition of different concentrations of mentha pulegium oil at $25{ }^{\circ} \mathrm{C}$. 
The Nyquist plots for this compound are shown in Fig. 3 and the corresponding circuit is shown in Fig. 4.

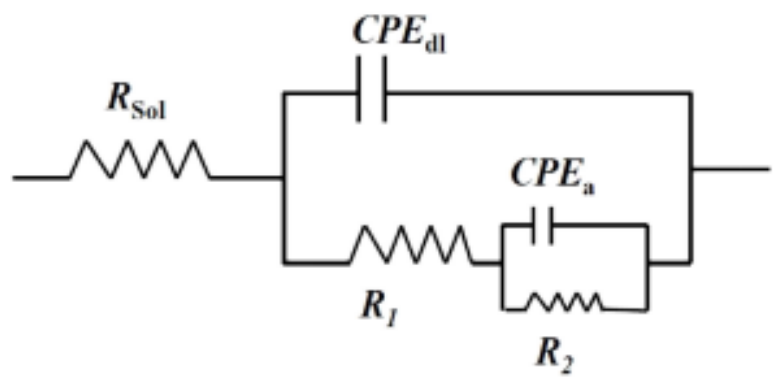

Figure 4. Electrical equivalent circuit (EEC) for aluminum in phosphoric acid media.

Nyquist plots

Every spectrum shows two capacitive loops. A first large well-trained high frequency loop and a small low frequency loop.

The inhibition efficiency was calculated using the Equation 2:

$$
I E=\frac{\bar{R}^{r} T-R T}{R^{r} T} X 100
$$

Where, R'T and RT are respectively the charge transfer resistance of aluminum in $2 \mathrm{M}$ phosphoric acid in the presence and absence of inhibitor. The impedance parameters are given in Table 3.

Table 3. Impedance parameters for corrosion of aluminum in $2 \mathrm{M}$ phosphoric acid containing different concentration of inhibitor at $25^{\circ} \mathrm{C}$.

\begin{tabular}{cccc}
\hline Cinh $[\mathbf{p p m}]$ & RT $\left[\mathbf{o h m . c m}{ }^{2}\right]$ & $\mathbf{C d I}\left[\boldsymbol{\mu F} / \mathbf{c m}^{2}\right]$ & $\mathbf{E I}[\%]$ \\
\hline Blank & 54.25 & 23.46 & ---- \\
1000 & 158.00 & 8.042 & 65.66 \\
1200 & 170.40 & 7.991 & 68.16 \\
1400 & 177.20 & 7.97 & 69.38 \\
1600 & 178.90 & 7.47 & 69.67 \\
1800 & 245.50 & 4.096 & 77.90 \\
\hline
\end{tabular}

The relationship between the double layer capacity (Cdl) and the maximum frequency (fmax) of the imaginary component of the impedance is shown in Equation 3:

$$
C d l=\frac{1}{2 f \max R T}
$$

\section{Electrical equivalent circuit}

In the circuit, in Fig. 4, Rsol represents the solution resistance of the system, $\mathrm{R}_{1}$ is the charge transfer resistance for the corrosion reaction and the double layer resistance, and $\mathrm{CPE}_{\mathrm{dl}}$ is the capacitance of the electrical double layer at the metal-solution interface, corresponding to the high frequency capacitive loop. $\mathrm{R}_{2}$ and $\mathrm{CPE}_{\mathrm{a}}$ represent the pseudo resistance and pseudo capacitance of the blasters layer. 


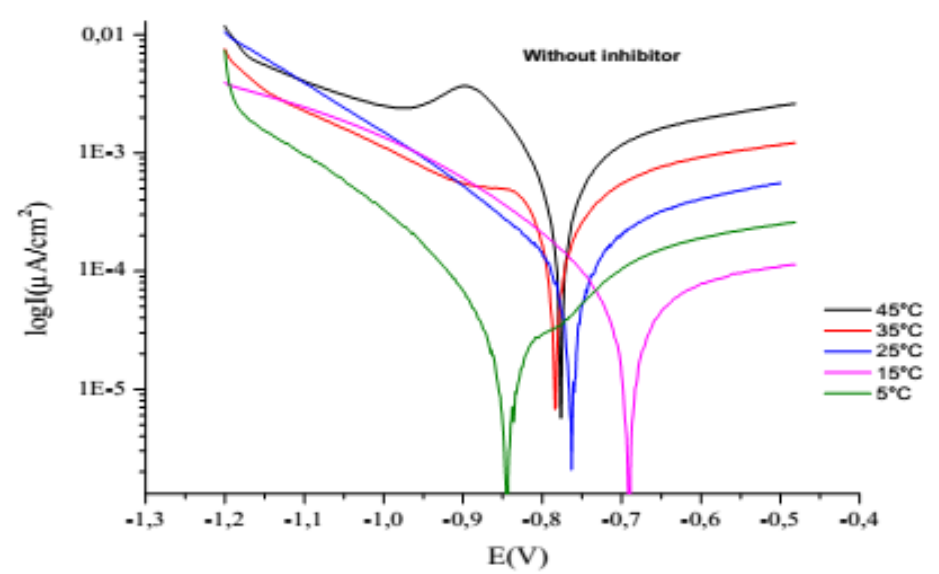

Figure 5. Electrical equivalent circuit (EEC) for aluminum in phosphoric acid media.

\section{Effect of temperature}

The polarization experiments were also used to investigate the effect of temperature on the corrosion behavior of aluminum in $2 \mathrm{M}$ phosphoric acid with and without inhibitor at a concentration of $1800 \mathrm{ppm}$, in the temperature range of $278^{\circ} \mathrm{K}-318^{\circ} \mathrm{K}$. Tafel curves are represented in Fig. 5 and Fig. 6. Results obtained are reported in Table 4.

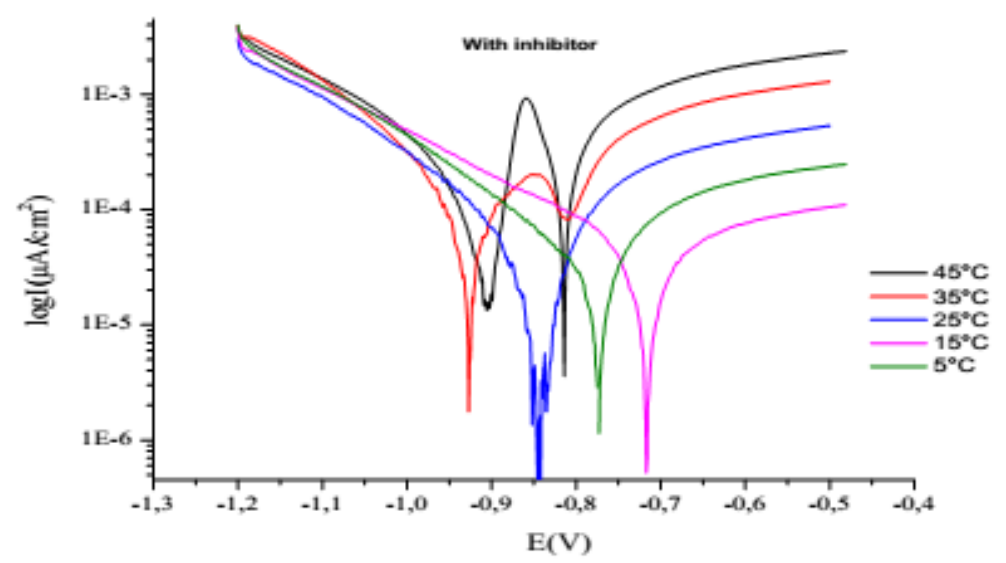

Figure 6. Polarization curves for aluminum corrosion in $2 \mathrm{M}$ phosphoric acid with 1800 ppm of mentha pulegium essential oil at studied temperatures.

\section{Discussion}

\section{Polarization curves}

From Fig. 2 and Table 2, it can be observed that, with the addition of this oil, the corrosion rate of aluminum decreases with an increase in the concentration of the inhibitor. Therefore, the inhibitor efficiency increases with an increase in the concentration of the inhibitor.

The changes observed in the polarization curves after the addition of the inhibitor are usually used as the criteria to classify inhibitors as cathodic, anodic or mixed [14]. According to literature report, when the corrosion potential is more than \pm $85 \mathrm{mV}$, with respect to the corrosion potential of the blank, the inhibitor can be considered distinctively as either cathodic or anodic type $[14,15]$. However, the minimum displacement in this study is more than $\pm 85 \mathrm{mV}$. 
This suggests that the essential oil of mentha pulegium oil functions as a cathodic-type inhibitor.

Table 4. Effect of temperature on aluminum corrosion behavior in presence and absence of studied inhibitor.

\begin{tabular}{ccccc}
\hline Cinhi [ppm] & Temperature [K] & Ecorr $[\mathbf{m V}]$ & $\begin{array}{c}\text { Icorr } \\
{\left[\boldsymbol{\mu A} / \mathbf{c m}^{2}\right]}\end{array}$ & EI [\%] \\
\hline Blank & 278 & -693.1 & 34.4996 & ------- \\
& 288 & -832.1 & 55.3139 & ------ \\
& 298 & -765.8 & 177.7441 & ----- \\
& 308 & -912.7 & 186.5601 & ------ \\
$1800^{[a]}$ & 318 & -779.2 & 300.4000 & ---- \\
& 278 & -718.9 & 21.8783 & 36.58 \\
& 288 & -776.2 & 33.2443 & 39.89 \\
& 308 & -847.3 & 37.1355 & 79.10 \\
& 318 & -929.4 & 60.9609 & 67.32 \\
& -816.8 & 122.2540 & 59.30 \\
\hline
\end{tabular}

${ }^{[a]}$ the concentration of inhibitor at which the efficiency is maximum at $25^{\circ} \mathrm{C}$.

\section{Electrochemical impedance spectroscopy}

Observing Figure 3, the diameter of the capacitive loop increases with the increase in the inhibitor concentration. This indicates that the impedance of the inhibited substrate has increased with the inhibitor concentration. The fact that impedance plots are semicircles both in the absence and in the presence of the inhibitor indicates that the corrosion process is charge transfer controlled [16].

From Table 3, the Cdl (double layer capacitance) values decrease with an increase in inhibitor concentrations, which could be due to the formation of a protective layer by inhibitor molecules [17].

\section{Effect of temperature}

On Table 4, it is observed that the corrosion rate (Icorr) increases with an increase of temperature in the presence and absence of the inhibitor. At low temperatures, the inhibitor efficiency EI increases with an increase of temperature. This can be due to the adsorption of inhibitor molecules on aluminum surface [18]. At elevated temperatures, the efficiency of the inhibitor decreases with an increase of temperature. This decrease in inhibition performance of the inhibitor is due to desorption of the adsorbed inhibitor molecules from aluminum surface [18].

\section{Thermodynamic parameters}

The corrosion inhibition of aluminum in $\mathrm{M}$ phosphoric acid can be more explained in terms of molecular adsorption of inhibitor on its' surface [18].

The value of apparent activation energy (Ea), in both presence and absence of inhibitor, was calculated from Arrhenius equation:

$$
\log I=\frac{-E a}{2,303 R T}+\log \lambda
$$


where, Ea is the apparent activation energy $\left(\mathrm{kJmol}^{-1}\right), \mathrm{R}$ is the molar gas constant $\left(8.314 \mathrm{JK}^{-1} \mathrm{~mol}^{-1}\right)$, $\mathrm{T}$ is the absolute temperature $(\mathrm{K})$, and $\lambda$ is the Arrhenius preexponential factor.

The Arrhenius plots give a straight line between LnI vs. 1000/T, as shown in Fig. 7. The Ea values were calculated by multiplying the slope of Arrhenius plots (LnI vs. 1000/ T) by R, represented in Table 5, from which it is noticed that the activation energy is greater $\left(40.98 \mathrm{kJmol}^{-1}\right)$ in absence of the inhibitor than in presence of $1800 \mathrm{ppm}$ of the inhibitor $\left(29.48 \mathrm{kJmol}^{-1}\right)$. This shows the chemical adsorption of the inhibitor and the effective formation of a surface film $[8,19]$.

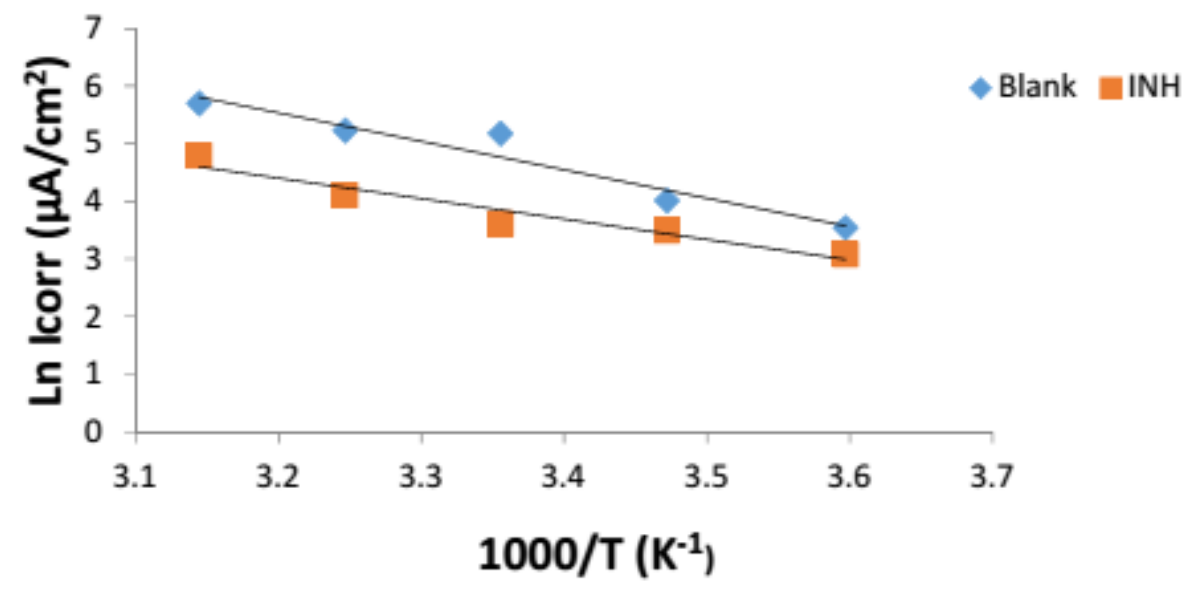

Figure 7. Arrhenius plots for aluminum in $2 \mathrm{M}$ phosphoric acid in absence and in presence of $1800 \mathrm{ppm}$ of mentha pulegium essential oil.

The corrosion current intensity dependency on temperature can also be represented by the transition state equation:

$$
\operatorname{Icorr}=\frac{\hbar T}{N h} X \exp \left(\frac{\Delta S *}{R}\right) X \exp \left(\frac{\Delta H *}{R T}\right)
$$

where, $\Delta \mathrm{H}^{*}$ is the apparent enthalpy of activation, $\Delta \mathrm{S}^{*}$ the apparent entropy of activation, $h$ is the Planck's constant and $N$ is the Avogadro number. The transition state plots, in Figure 8 , give a straight line between Ln (I/T) vs. $1000 / T$. From the slope of $\left(-\Delta H^{*} / \mathrm{R}\right)$ and intercept of $\left[\mathrm{Ln}(\mathrm{R} / \mathrm{Nh})+\left(\Delta \mathrm{S}^{*} / \mathrm{R}\right)\right]$, values of $\Delta \mathrm{S}^{*}$ and $\Delta \mathrm{H}^{*}$ were calculated and listed in Table 5.

Table 5. Thermodynamic parameters for aluminum corrosion in $2 \mathrm{M}$ phosphoric acid in the absence and presence of the inhibitor at different studied temperatures.

\begin{tabular}{|c|c|c|c|}
\hline Cinh [ppm] & Ea $\left[k J . m o l^{-1}\right]$ & $\Delta S *[\mathrm{~J} / \mathrm{mol} . \mathrm{K}]$ & $\Delta H^{*}\left[\mathrm{~kJ} . \mathrm{mol}^{-1}\right]$ \\
\hline Blank & $40-98$ & -137.3 & 38.5 \\
\hline 1800 & 29.48 & -183.5 & 27.02 \\
\hline
\end{tabular}

From Table 5, $\Delta \mathrm{H}^{*}$, in both absence and presence of the inhibitor, are positive. This reflects the endothermic process of adsorption of this inhibitor on aluminum surface, suggesting that higher temperature favors the corrosion process [20].

The negative values of $\Delta \mathrm{S}^{*}$ may reflect the association mechanism of corrosion, i.e., the decrease in disorder takes place on going from reactants to the activated 
states. It has also been noticed that the addition of the inhibitor to the test solution gives lesser negative values of $\Delta \mathrm{S}^{*}$ than in the absence of the inhibitor, i.e., it decreases the corrosion rates. This result may be considered as an indirect evidence to support the cited proposed mechanism [21].

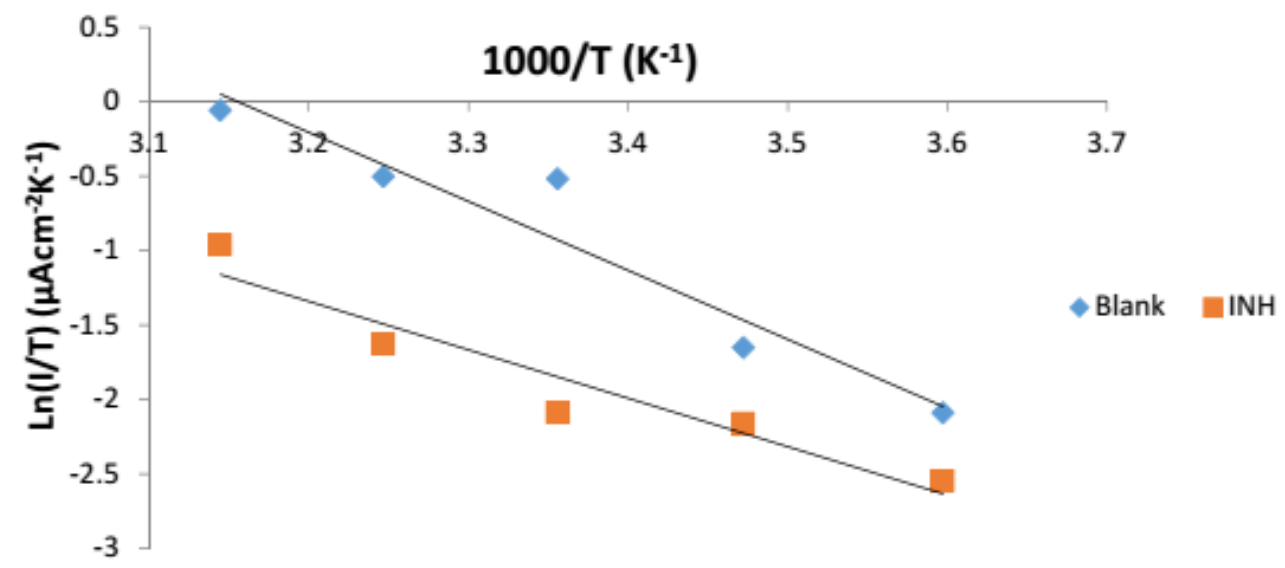

Figure 8. Transition state plots for aluminum in $2 \mathrm{M}$ phosphoric acid in absence and in presence of $1800 \mathrm{ppm}$ of mentha pulegium essential oil.

\section{Conclusions}

- Mentha pulegium leaves essential oil is a good aluminum corrosion inhibitor in $2 \mathrm{M}$ phosphoric acid solution. Its effectiveness increases with an increase of concentration, reaching the maximum efficiency of $79 \%$ at $1800 \mathrm{ppm}$ by potentiodynamic polarization studies. The effectiveness decreases with an increase in temperature.

- Polarization results indicate the cathodic type of the used inhibitor.

- Impedance plots shape indicates that the corrosion process is charge transfer controlled.

- According to thermodynamic parameters and due to the addition of $1800 \mathrm{ppm}$ of the inhibitor, the apparent activation energy ( $\left.\mathrm{Ea}^{*}\right)$ shows the chemical nature of the adsorption of the studied oil on aluminum. The apparent enthalpy of activation $\left(\Delta \mathrm{H}^{*}\right)$ proves that the same adsorption is an endothermic process and the apparent entropy of activation $\left(\Delta \mathrm{S}^{*}\right)$ confirms the decrease of corrosion rate.

\section{References}

1. Constantin F. PhD Thesis. Lyon, France: INSA; 2011.

2. Halambek J, Zutinic A, Berkovic K. Int J Electrochem Sci. 2013;8:1120111214.

3. Musa AY. Recen Reseac Corr Evalu Protec. 2012.

4. Bensabah F, Houbairi S, Essahli M, et al. Port Electochim Acta. 2013;31:195-206.

5. Fares MM, Maayta AK, A-Qudah MM. Corros Sci. 2012;60:112-117.

6. Deng S, Li X. Corros Sci. 2012;64:253-262. 
7. Haleem SMAE, Wanees SAE, Aal EEAE. Corros Sci. 2013;68:1-13.

8. Houbairi S, Lamiri A, Essahli M, Chem Sci Rev Lett. 2014;3:353-366.

9. Darwich E, Benziane Z, Taouil R. Chem Bull "POLITEHNICA" Univ (Timisoara). 2010;55:103-106.

10. Boukhebti H, Chaker AN, Belhadj H, et al. D Pharma Lett. 2011;3:267-275.

11. Erhan MK, Bölükbaşi SC, Ürüşan H. Liv Stoc Sci. 2012;146:189-192.

12. Teixeira B, Marques A, Ramos C, et al. Indust Crop Prod. 2012;36:81-87.

13. Prabhu D, Rao P. J Environ Chem Eng. 2013;1:676-683.

14. Zarrouk A, Zarrok H, Salghi R, et al. J Mater Environ Sci. 2013;4:177-192.

15. Ameer MA, Ghoneim AA, Fekry AM. Int. J. Electrochem.Sci. 2012;7:4418-4431.

16. Hmamou DB, Salghi R, Zarrouk A, et al. D Pharma Lett. 2013;5:135-142.

17. Victoria SN, Prasad $R$, Manivannan $R$. Int $J$ Electrochem Sci. 2015;10:2220-2238.

18. Korbe $\mathrm{R}$, Verma CB, Ebenso EE, et al. Int $\mathrm{J}$ Electrochem Sci. 2015;10:1081-1093.

19. Bhola SM, Singh G, Mishra B. Int J Electrochem Sci. 2013;8:5635-5642.

20. Vashi RT, Naik D. E-J Chem. 2010;7(S1):S1-S6.

21. Hassan RM, Zaafarany IA. Materials. 2013;6:2436-2451. 